\title{
Kinetic Behavior of the Adsorption of Malachite Green Using Jordanian Diatomite as Adsorbent
}

\author{
Emad El Qada \\ Chemical Engineering Department, Mu'tah University, Karak, 61710 Jordan
}

\begin{abstract}
The main intention of this work is to study the adsorption rate and mechanism for the adsorption of Malachite Green dye (MG) onto Jordanian diatomite. A series of experiments were conducted under a variety of conditions such as the mass of diatomite, initial MG concentration, and $\mathrm{pH}$ of the solution. The mechanism of adsorption was elucidated based on different kinetic models. Experimental conditions showed a considerable effect on the adsorption rate. Alkali conditions promote MG uptake and increase the rate of adsorption. Approximately $99 \%$ of dye removal was achieved as the diatomite dosage increased from $0.25 \mathrm{~g}$ to $1.5 \mathrm{~g}$. The adsorption rate-controlling step was found to be a combination of chemisorption and intraparticle diffusion, with the external mass transfer predominating in the first five minutes of the experiment.
\end{abstract}

Keywords: Adsorption; Malachite green; Diatomite; Kinetic model; Biot Number.

\section{Introduction}

Elimination of dyes from wastewater is vitally an important environmental issue and has to gain attention. Adsorption technology is considered as a powerful and promising treatment technique for a wide range of pollutants including dyes (Hasanzadeh et al., 2019; Georgiadis et al., 2013; Sartape et al., 2017; Dhahir et al., 2013). Generally, three consecutive steps are involved in the solidliquid adsorption process and include (Lazaridis and Asouhidou, 2003; Nethajia et al., 2010): i) Boundary layer or film diffusion: pollutant is transferred from the bulk solution through the liquid film to the exterior surface of the adsorbent; ii) Intraparticle diffusion: diffusion of pollutant into the pore of adsorbent or sorption on the external surface; and iii) Adsorption at a site: adsorption of pollutant on the interior surfaces of pores and capillary spaces of the adsorbent.

Since the third step is generally very rapid compared to the first and the second step, the adsorption processes are usually controlled by either film or intraparticle diffusion or both (Nethajia et al., 2010). If the external transport is greater than the internal transport, the adsorption process is controlled by intraparticle diffusion. Whereas if the external transport is less than internal transport, the adsorption process is controlled by film diffusion. When the external transport is almost equal to the internal transport, the transport of the pollutants to the boundary may not be promising at a significant rate (Mittal, 2006).

The knowledge of the adsorption capacity and adsorption rate is of paramount importance to gain a better understanding of the adsorption process. Even though equilibrium studies determine the maximum adsorption capacity of the adsorbent and very helpful in determining the efficiency of the adsorption process, the efficiency is also strongly dependent on the adsorption system's kinetics (Regazzoni, 2019; Krishnan and Anirudhan, 2002; Rudzinski and Plazinski, 2001).

Furthermore, adsorption kinetics is of paramount importance when designing adsorption systems. It helps the designer to select the appropriate adsorbent and applying it correctly. The kinetic study is also of crucial importance in determining the mechanism of the adsorption process and provides valuable information regarding the adsorption rate and the factors affecting the adsorption rate (Guo and Wang, 2019; Pan and Zhang, 2009).

Many investigators have reported the significance of the adsorption kinetics (Sartape et al., 2017; Arivoli et al., 2009; Pan and Zhang, 2009; Hema and Arivoli, 2008; Ho, 2006). Thus, a deep understanding of the adsorption kinetics is essential to assess the performance of the adsorption system. Equilibrium aspects of the adsorption of MG onto Jordanian diatomite have been studied and discussed.

Detailed information about the equilibrium study is well documented in (El Qada, 2019). However, the adsorption kinetics of the Jordanian diatomite-MG adsorption system has not been reported in the literature (Alali, 2015). Therefore, as a continuation of the equilibrium study and to complete the adsorption process aspects of MG onto Jordanian diatomite, the present study is intended to understand the mechanism of the transport processes that govern the removal of MG from aqueous solution and the parameters affecting the adsorption rate. 


\section{Materials and Methods}

\subsection{Materials:}

Malachite Green dye $\left(\mathrm{C}_{23} \mathrm{H}_{25} \mathrm{~N}_{2} \mathrm{Cl}\right)$ and Jordanian diatomite were used in this study as adsorbate and adsorbent, respectively. More information about them is reported elsewhere (El Qada, 2019).

\subsection{Kinetic Adsorption:}

Several kinetic adsorption experiments were conducted to investigate the rate and mechanism of MG adsorption onto Jordanian diatomite. The effect of $\mathrm{pH}$, initial dye concentration, and diatomite mass was studied to assess the time dependence of the adsorption process. An agitated glass beaker of the internal diameter of $0.13 \mathrm{~m}$ and with a capacity of $2 \mathrm{dm}^{3}$ solutions was used. The beaker was equipped with four-blade glass impellers driven by the electric motor to stir MG solution and diatomite. Four baffles were fixed evenly around the circumference of the adsorber to ensure complete mixing and preclude vortex formation during the experiment. The progress of MG adsorption was determined by measuring the absorbance of the MG at different time intervals using Varian Cary-50 UV/VIS spectrophotometer (USA). All the kinetics experiments were performed at room temperature.

The amount of MG adsorption at the time, t, was calculated using Eq. (1):

$$
q_{t}=\frac{\left(C_{o}-C_{t}\right) V}{m}
$$

where $q_{t}$ is the amount of MG adsorbed at time $\mathrm{t}(\mathrm{mg} / \mathrm{g}) ; C_{o}$ is the initial dye concentration $\left(\mathrm{mg} / \mathrm{dm}^{3}\right), C_{t}$ is the concentration of MG solution at time $\mathrm{t},\left(\mathrm{mg} / \mathrm{dm}^{3}\right) ; m$ is mass of the diatomite $(\mathrm{g})$ and $V$ is the volume of MG solution $\left(\mathrm{dm}^{3}\right)$. Table 1 lists the experimental conditions used in performing kinetics adsorption experiments. The kinetic data were then analyzed by fitting it to different kinetic models in an attempt to elucidate the rate and adsorption mechanism of MG onto Jordanian diatomite. Out of several kinetic models available, the most common ones namely, external mass transfer model, pseudosecond-order kinetic model, intraparticle diffusion model, Boyd model, and Elovich model were used. Transport numbers and Biot numbers were also utilized. The applicability of the kinetic models was compared by judging the regression coefficients, $\mathrm{r}^{2}$.

Table 1 Experimental conditions of adsorption kinetics.

\begin{tabular}{cccc}
\hline $\begin{array}{c}\text { Initial dye } \\
\text { concentration } \\
(\mathrm{ppm})\end{array}$ & $\begin{array}{c}\text { Particle size } \\
(\mu \mathrm{m})\end{array}$ & $\begin{array}{c}\text { Mass of } \\
\text { adsorbent } \\
(\mathrm{g})\end{array}$ & $\begin{array}{c}\text { pH of dye } \\
\text { solution }\end{array}$ \\
\hline 25 & $500-710^{*}$ & 0.25 & 5.00 \\
50 & $250-500$ & 0.50 & $7.00^{*}$ \\
$100^{*}$ & $25-250$ & $0.75^{*}$ & 9.00 \\
150 & -------- & 1.50 & 11.0 \\
\hline
\end{tabular}

* Standard conditions

\section{Results and Discussion 2.1 Effect of Solution pH:}

To study the effect of $\mathrm{pH}$ on the adsorption kinetics of MG onto Jordanian diatomite, different values of $\mathrm{MG}$ solution $\mathrm{pH}$ were prepared (5-11). The result of the $\mathrm{pH}$ effect on the adsorption of MG from aqueous solution is shown in Figure 1. The MG uptake is seen to be favored at the basic condition. A significant increase in the adsorption rate is noticeable at the higher values of solution $\mathrm{pH}$. MG uptake was increased from $110 \mathrm{mg} / \mathrm{g}$ to $182.5 \mathrm{mg} / \mathrm{g}$ in 20 minutes as the $\mathrm{pH}$ increased from 5 to 11 . Besides, the adsorption efficiency was increased from $62.8 \%$ to $98.5 \%$ for an equilibrium time of $45 \mathrm{~min}$. This indicates that solution $\mathrm{pH}$ plays an essential role in the adsorption process. As the solution $\mathrm{pH}$ was changed from the acidic range to the alkaline range, the diatomite surface became negatively charged which in turn promoted the adsorption of the positively charged dye (MG) and thus increased the rate of the adsorption process. These results agree

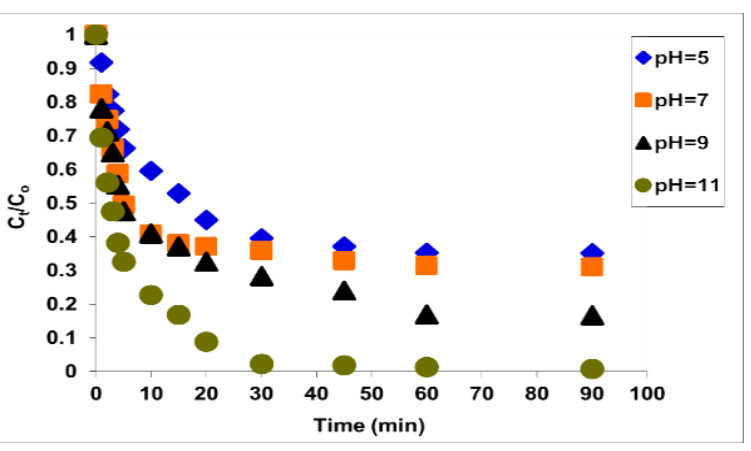

Fig. 1 Effect of solution $\mathrm{pH}$ on the adsorption rate of MG onto diatomite, concentration $100 \mathrm{ppm}$, agitation agitation 300 rpm, temperature $25^{\circ} \mathrm{C}$, size $500-710 \mu \mathrm{m}$, mass $0.75 \mathrm{~g}$, and volume $1.7 \mathrm{dm}^{3}$ well with previously reported results on the adsorption of MG onto organoclay (Ullah et al., 2017). Moreover, another study (Song et al., 2015) supports these findings. Hence, they found that by lowering the solution $\mathrm{pH}$, the amount $\mathrm{MG}$ sequestered from the solution was reduced and they attributed this trend to the neutralization effect of excess $\mathrm{H}^{+}$ions present in the acidic medium which neutralizes the negative charge at the surface of the 
adsorbent. Increasing solution $\mathrm{pH}$ usually reduce the protonation process and supply more vacant negatively charged adsorption sites required for the adsorption of cationic dye.

\subsection{Effect of Initial Dye Concentration:}

It is well-recognized in the adsorption field that the initial dye concentration plays a significant role in controlling the rate of the adsorption process. For a better understanding of this role, various initial dye concentrations $(25,50,100$ and $150 \mathrm{ppm})$ were utilized in different kinetic experiments. Figure 2 depicts the effect of the initial MG concentration on the adsorption rate of the MG-diatomite system. The kinetic data reveals that there is a direct relationship between the adsorption capacity and the initial dye concentration. The adsorption capacity was increased. This is consistent with the results obtained previously (Song et al., 2015; Chiou and Li, 2002; Santhi et al., 2015). On the contrary, the percentage removal of MG from the aqueous solution was dropped from $99.9 \%$ to $66.4 \%$ as the

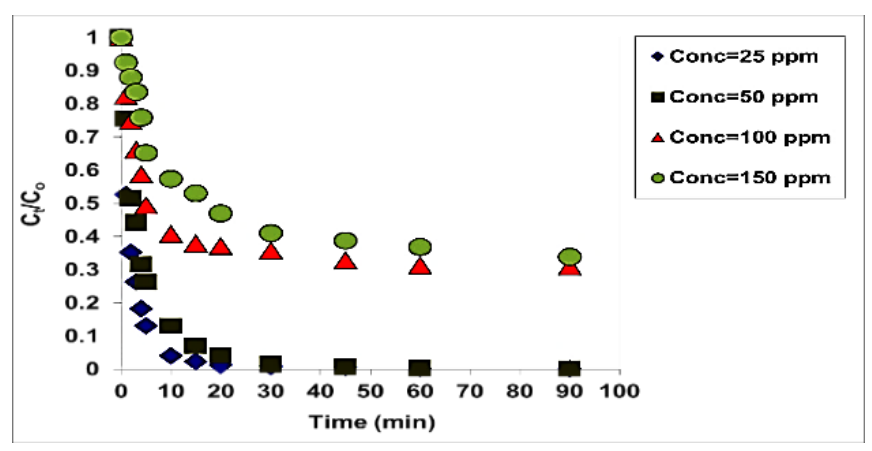

Fig. 2 Effect of initial dye concentration on the adsorption rate of MG onto diatomite. Mass $0.75 \mathrm{~g}$, agitation $300 \mathrm{rpm}$, temperature $25^{\circ} \mathrm{C}$, size 500-710 $\mu \mathrm{m}$, mass $0.75 \mathrm{~g}, \mathrm{pH} 7$, and volume $1.7 \mathrm{dm}^{3}$ initial MG concentration increased from $25 \mathrm{ppm}$ to $150 \mathrm{ppm}$.

Another study reported a similar trend and suggested that there is a fixed number of adsorption sites, so at low initial dye concentration, few dye molecules will be available which can easily access a higher number of the available adsorption sites and this, in turn, raise the adsorption efficiency (Ullah et al., 2017). This quantity of accessible sites is less in the case of higher dye concentration because of the competition between dye molecules for the fixed number of adsorption sites, thus some of the dye molecules did not get absorbed and remain in the solution causing the reduction in the adsorption efficiency. It is also evident that more time is required to reach the equilibrium state at higher initial MG concentrations. 15 minutes were enough to reach equilibrium in the case of $25 \mathrm{ppm}$ solution, whereas 45 minutes were required for the 150-ppm solution. The higher the initial MG concentration, the slower the decrease in the dimensionless concentration $\left(C_{t} / C_{o}\right)$. At high initial dye concentration, more $\mathrm{MG}$ molecules are available in the system which means strong competition between MG for the available adsorption sites.

\subsection{Effect of the mass of adsorbent}

Different kinetic adsorption experiments were performed to study the effect of diatomite concentration on the removal of MG from aqueous solution. Different masses of diatomite ranging from 0.25-1.500 (g) were used. Other experimental factors were kept constant. The effect of the diatomite concentration on the removal of MG is reported in Figure 3. It can be observed from Figure 3 that there is a direct proportionality between the rate of the adsorption and the concentration of diatomite. The removal efficiency at equilibrium increased from $44.2 \%$ to $99.36 \%$ when the diatomite dose was increased from 0.25 $\mathrm{g}$ to $1.5 \mathrm{~g}$. The opposite trend was obtained for the adsorption capacity. Diatomite adsorption capacity was decreased from $176.8 \mathrm{mg} / \mathrm{g}$ to $99.35 \mathrm{mg} / \mathrm{g}$ as the diatomite dose increased from $0.25 \mathrm{~g}$ to $1.5 \mathrm{~g}$. The increase in the adsorption efficiency can be explained by the increase in the binding sites available on the adsorbent surface at a higher dosage of diatomite (Shirmardi et al., 2013). While the decrease in diatomite capacity can be attributed to the fact that increasing the diatomite dose and fixing the dye concentration resulted in

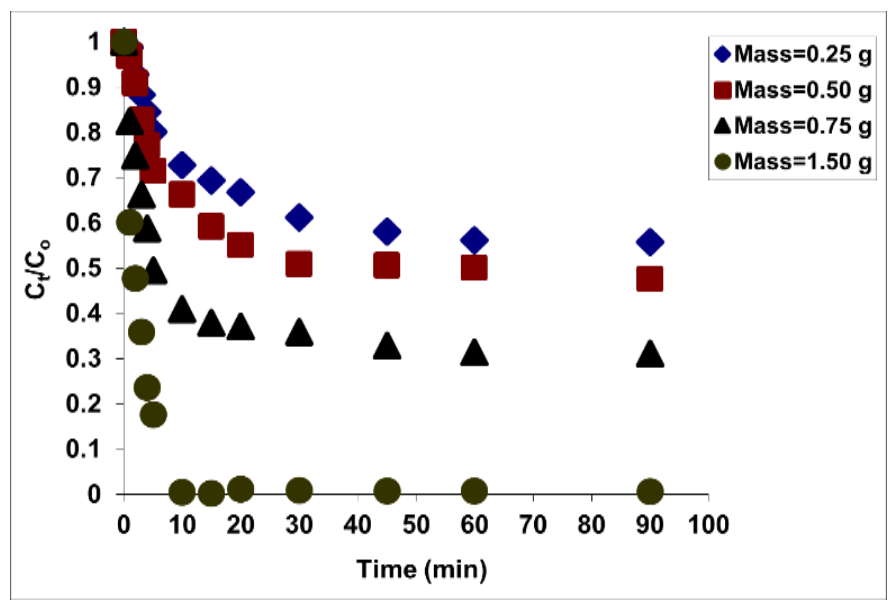

Fig. 3 The effect of diatomite concentration on the adsorption rate of MG onto diatomite. Temperature $25^{\circ} \mathrm{C}$, size $500-710 \mu \mathrm{m}$, concentration 100 $\mathrm{mg} / \mathrm{dm}^{3}, \mathrm{pH}$, agitation $300 \mathrm{rpm}$ and volume $1.7 \mathrm{dm}^{3}$. unoccupied adsorption sites at higher dosages of diatomite and thus reducing the diatomite adsorption capacity (Ullah et al., 2017). It is also clear that by increasing diatomite dose the curve becomes steeper which means a faster rate of adsorption. Numerous studies have been mentioned that by increasing the adsorbent dosage, the adsorption rate increases (Litefti et al., 2017; Aazza et al., 2017; Sawasdee and Watcharabundit, 2015). Besides, the obtained kinetics results showed that high adsorption rates were attained in the first five minutes followed by gradual removal at a lower rate until equilibrium. This behavior can be attributed to the rapid attachment of MG on the surface of diatomite within the first five minutes. Thereafter, the diatomite surface was saturated by MG molecules and the dye molecules start to diffuse through 
the pores (intraparticle diffusion). Results reported in (Sawasdee and Watcharabundit, 2015) illustrated that the rapid dye removal in the initial stage is due to the abundant availability of active sites on the adsorbents surface, once these sites are gradually occupied, the adsorption process became less efficient. On the other hand, another study (Benmaamar et al., 2016), attributed the slower gradual removal of dye molecules after the lapse of time to the repulsion forces between the dye molecules adsorbed on the solid and dye molecules in the liquid phase which makes it took a long time to reach equilibrium.

\subsection{Adsorption Kinetics Modelling 2.4.1 Furusawa-Smith Model}

To explore the significance of the external mass transfer resistance on the adsorption rate of MG onto Jordanian diatomite, the Furusawa-Smith model was utilized. The model depicts the relation between the mass transfer coefficient and the change in the liquid phase concentration with time. High values of external mass transfer coefficient usually reflect low resistance to the mass transfer experienced by the adsorbate as it transfers from the liquid phase to the solid phase. The mass transfer coefficient was determined using the linearized form of Furusawa-Smith model (Furusawa, and Smith, 1973):

$$
\operatorname{Ln}\left(\frac{C_{t}}{C_{o}}-\frac{1}{1+m_{s} k_{L}}\right)=\operatorname{Ln}\left(\frac{m_{s} k_{L}}{1+m_{s} k_{L}}\right)-\left(\frac{1+m_{s} k_{L}}{m_{s} k_{L}}\right) \cdot k_{f} S_{s} t
$$

where $C_{t}$ is the liquid-phase concentration at time $t\left(\mathrm{mg} / \mathrm{dm}^{3}\right) ; C_{\mathrm{o}}$ is the initial phase concentration $\left(\mathrm{mg} / \mathrm{dm}^{3}\right) ; k_{\mathrm{L}}$ is a Langmuir constant $\left(\mathrm{dm}^{3} / \mathrm{g}\right) ; m_{\mathrm{s}}$ is the concentration of adsorbent $\left(\mathrm{g} / \mathrm{dm}^{3}\right) ; S_{\mathrm{s}}$ is the specific surface area $\left(\mathrm{m}^{-1}\right) ; t$ is the time (min), and $k_{\mathrm{f}}$ is the external mass transfer coefficient $\left(\mathrm{m} \cdot \mathrm{min}^{-1}\right)$.

Table 2 External mass transfer coefficient for the adsorption of MG onto diatomite.

\begin{tabular}{|c|c|c|c|c|c|c|c|c|}
\hline $\begin{array}{c}\text { Variable } \\
\mathrm{pH}\end{array}$ & $\begin{array}{l}\mathrm{K}_{\mathrm{f}} \times 10^{3} \\
\left(\mathrm{~m} \cdot \mathrm{min}^{-1}\right)\end{array}$ & $\mathrm{r}^{2}$ & $\begin{array}{l}\text { Conc. } \\
(\mathrm{ppm})\end{array}$ & $\begin{array}{l}\mathrm{K}_{\mathrm{f}} \times 10^{3} \\
\left(\mathrm{~m} \cdot \mathrm{min}^{-1}\right)\end{array}$ & $r^{2}$ & Mass (g) & $\begin{array}{l}\mathrm{K}_{\mathrm{f}} \times 10^{3} \\
\left(\mathrm{~m} \cdot \mathrm{min}^{-1}\right)\end{array}$ & $r^{2}$ \\
\hline 5 & 1.748 & 0.9960 & 25 & 11.80 & 0.9200 & 0.25 & 1.482 & 0.9840 \\
\hline $7 *$ & 2.212 & 0.9900 & 50 & 5.081 & 0.9930 & 0.500 & 1.599 & 0.9840 \\
\hline 9 & 2.540 & 0.9960 & 150 & 1.283 & 0.9480 & 1.500 & 3.015 & 0.9900 \\
\hline 11 & 3.272 & 0.9950 & ------- & ------ & ------ & ------- & -------- & ------- \\
\hline
\end{tabular}

* Standard experimental conditions, concentration 100 ppm, pH 7, agitation 300 rpm, particle size $500-710 \mu m$ and mass $0.75 \mathrm{~g}$.

Table 2 lists the values of the external mass transfer coefficient, $k_{\text {f }}$, for the adsorption of MG onto diatomite. The obtained results showed that increasing diatomite mass has led to a decrease in the external mass transfer resistance as can be seen from the increases in the $k_{f}$ values. Thus, the rate of MG adsorption onto diatomite was increased. Besides, increasing the solution $\mathrm{pH}$ also caused an increase in $k_{f}$ value and hence a decrease in the external mass transfer resistance. These findings are similar to other research results (Mckay et $a l .$, 1986). They illustrated that increasing adsorbent dosage will increase turbulence from the particles which in turn will increase the mobility of the adsorbate and facilitate their crossing through the boundary layer to the particle surface. An opposite trend was observed with the increase in the initial MG concentration. The mass transfer coefficient decreases as the initial MG concentration increases. Hence the initial rate of adsorption was decreased. This is probably due to the interactions between MG molecules in the solution and the

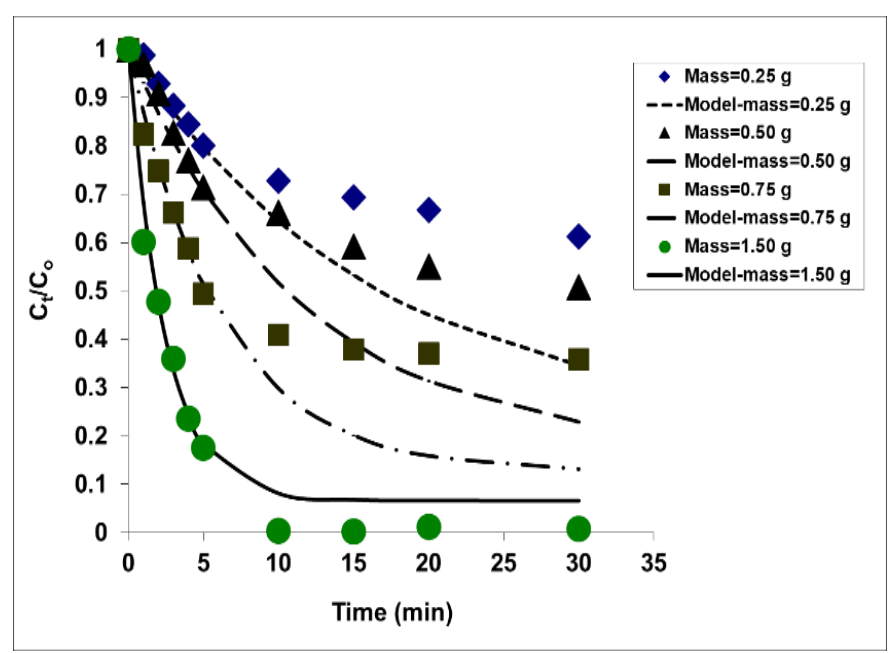

Fig. 4 Application of Furusawa-Smith model to the experimental data concentration $100 \mathrm{ppm}$, agitation $300 \mathrm{rpm}, \mathrm{pH}$ 7, size 500-710 $\mu \mathrm{m}$, volume $1.7 \mathrm{dm}^{3}$ and temperature $25^{\circ} \mathrm{C}$.

competition for the available adsorption sites overriding the increase in the driving force and at higher MG concentration (Girish and Murty, 2016). Figure 4 displays the application of the Furusawa-Smith model to the experimental data for the adsorption of MG onto diatomite at different adsorbent masses. The results show that the Furusawa-Smith model was able to predict the 
experimental data in the initial period (first 5 minutes) after which a noticeable deviation is evident. Furthermore, the calculated $q_{e}$ values are in great agreement with the experimental values during the first 5 minutes. This signifies that surface mass transfer was the controlling mechanism during the initial stage of the adsorption of MG, after which, the external mass transfer is no longer the predominant mechanism. Yakubu and Owabor (2018) reported that external film diffusion is the predominant mechanism during the initial period of the adsorption process.

\subsubsection{Intraparticle Diffusion Model}

Since the external mass transfer model failed to predict the kinetics data over the whole time interval, intraparticle mass transfer resistance is likely to be the rate-controlling step especially after the ending of the initial period of adsorption. Thus, the intraparticle diffusion model was employed to predict the experimental kinetics data. This model presumes the diffusion of adsorbate within the pore structure of the adsorbent. The expression of the intraparticle diffusion model is given in Eq. (3):

$$
q_{t}=k_{p} t^{0.5}+c
$$

where $c(\mathrm{mg} / \mathrm{g})$ is the intercept which is proportional to the boundary layer thickness; $q_{t}$ is the adsorption capacity (mg/g) and $k_{p}$ is the intraparticle diffusion rate constant $\left(\mathrm{mg} / \mathrm{g} . \min ^{1 / 2}\right) . k_{p}$ can be obtained from the slope of the plot of $q_{t}$ versus $\mathrm{t}^{0.5}$.

Numerous previous studies have shown that the plot of $q_{t}$ versus $\mathrm{t}^{0.5}$ represents multi-linearity and attributed this to the fact that two or more steps may be involved in the adsorption process (Arivoli et al., 2009). Figure 5 shows a plot of $q_{t}$ versus $t^{0.5}$ for the adsorption of MG onto diatomite at a concentration of $50 \mathrm{ppm}$. It is evident from the figure the multiple nature of the relationship between $q_{t}$ and $\mathrm{t}^{0.5}$. The multi-linearity in the plot may suggest that the adsorption process of MG onto Jordanian diatomite is not fully controlled by intraparticle diffusion and the adsorption may be proceeded by surface adsorption followed by intraparticle diffusion. Lazaridis and Asouhidou (2003) attributed the last stages to the chemical reaction which supports the findings of the pseudo-second-order model. Yakubu and Owabor (2018) and Heydaria and Khavarpour (2018) announced that if the plot of $q_{t}$ versus $t^{0.5}$ did not pass through the origin, this means that other steps may participate in the rate-controlling step. Figure 5 shows that the linear portion of the curve does not pass through the origin and this indicates that intraparticle diffusion is not the only predominant mechanism for the adsorption of MG onto diatomite. Large values of " $c$ " indicate the great contribution of surface adsorption in the rate-limiting step (Thilagavathi et al., 2015). Sharma et al. (2016) reported that higher values of " $c$ " indicate diffusion through the boundary layer is the rate-limiting step. Again, this supports the previous findings of the external mass transfer model as it was proved that the surface adsorption is predominant in the first five minutes. Figure $\mathbf{6}$ shows an excellent fit of the intraparticle diffusion model to the experimental data for the adsorption of MG onto diatomite at different concentrations, and Table 3 records the results for the determination of intraparticle diffusion rate constant, $k_{p}$ at different dosages of diatomite. Data from table 3 show that the value of $k_{p}$ decreased from 23.86 to $7.153\left(\mathrm{mg} \mathrm{g}^{-1} \mathrm{~min}^{-0.5}\right)$ as the diatomite mass increased from 0.25 to $1.5(\mathrm{~g})$. As the mass of diatomite increased, a rapid decrease in MG concentration occurred and thus, reduces the driving force required for intraparticle diffusion.

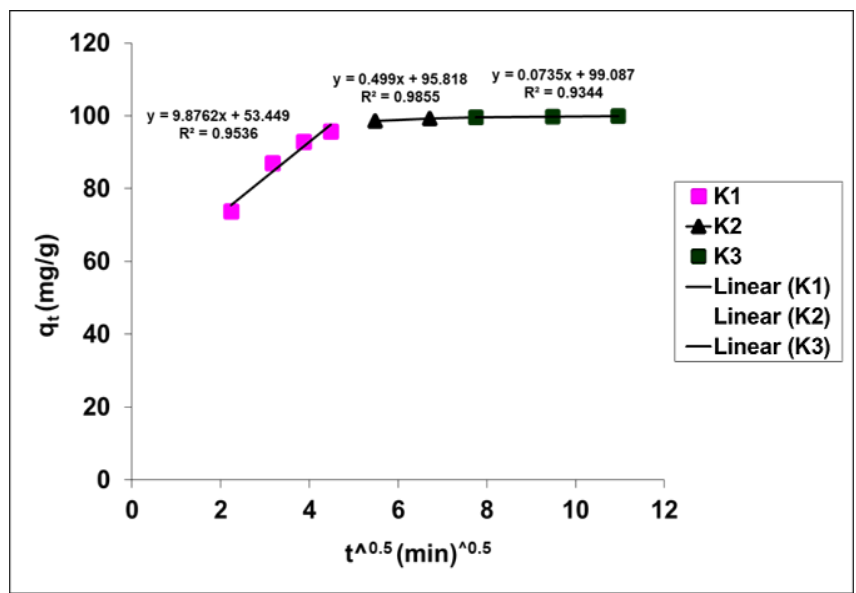

Fig. 5 Intraparticle diffusion effect on the adsorption of MG onto diatomite at concentration $50 \mathrm{ppm}$, agitation $300 \mathrm{rpm}$, mass 0.75 $\mathrm{g}$, temperature $25^{\circ} \mathrm{C}, \mathrm{pH} 7$, volume $1.7 \mathrm{dm}^{3}$ and size $500-710 \mu \mathrm{m}$.

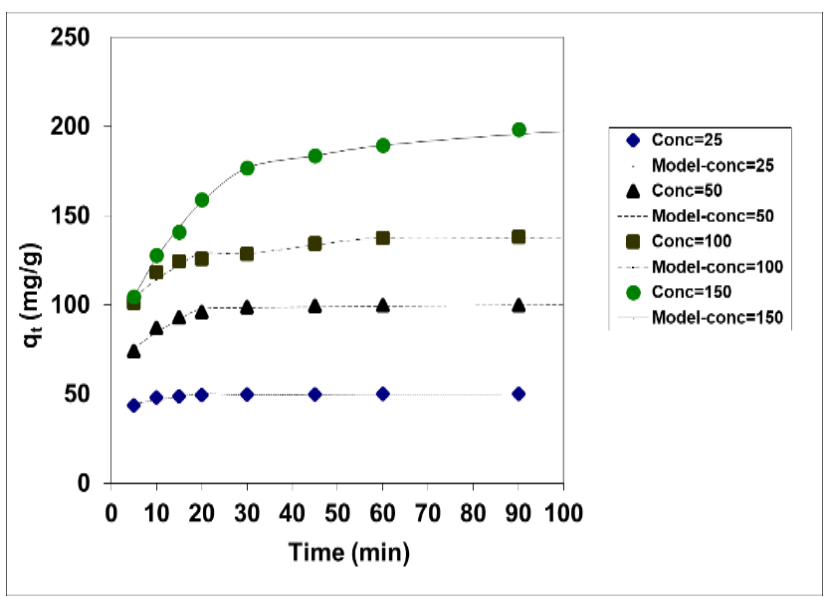

Fig. 6 Prediction of the intraparticle diffusion model to the experimental data. Temperature $25^{\circ} \mathrm{C}$, mass $0.75 \mathrm{~g}$, agitation $300 \mathrm{rpm}, \mathrm{pH} 7$, volume $1.7 \mathrm{dm}^{3}$ and size $500-710 \mu \mathrm{m}$. 
Table 3 Intraparticle diffusion rate constant, $k_{p}$, for the adsorption of MG onto diatomite as a function of the amount of diatomite.

\begin{tabular}{|c|c|c|c|c|c|c|c|c|c|}
\hline $\begin{array}{c}\text { Variable } \\
\text { Mass } \\
\text { (g) }\end{array}$ & $\begin{array}{c}\mathrm{k}_{\mathrm{p} 1} \\
\left(\mathrm{mg} \cdot \mathrm{g}^{-1}\right. \\
\left.\mathrm{min}^{-0.5}\right)\end{array}$ & $\begin{array}{c}\mathrm{c}_{1} \\
(\mathrm{mg} / \mathrm{g})\end{array}$ & $\mathrm{r}^{2}$ & $\begin{array}{c}\mathrm{k}_{\mathrm{p} 2} \\
\left(\mathrm{mg} \cdot \mathrm{g}^{-1}\right. \\
\left.\mathrm{min}^{-0.5}\right)\end{array}$ & $\begin{array}{c}\mathrm{c}_{2} \\
(\mathrm{mg} / \mathrm{g})\end{array}$ & $\mathrm{r}^{2}$ & $\begin{array}{c}\mathrm{k}_{\mathrm{p} 3} \\
\left(\mathrm{mg} \cdot \mathrm{g}^{-1}\right. \\
\left.\mathrm{min}^{-0.5}\right)\end{array}$ & $\begin{array}{c}\mathrm{c}_{3} \\
(\mathrm{mg} / \mathrm{g})\end{array}$ & $r^{2}$ \\
\hline 0.25 & 23.860 & 29.050 & 0.9780 & 8.9230 & 106.90 & 0.9910 & 0.4320 & 172.30 & 0.7130 \\
\hline 0.50 & 21.270 & 31.750 & 0.9870 & 1.0570 & 133.30 & 0.9280 & 2.4180 & 123.80 & 0.8710 \\
\hline $0.75^{*}$ & 11.110 & 79.120 & 0.9000 & 3.9280 & 107.20 & 0.9760 & 0.2830 & 135.00 & 0.9250 \\
\hline 1.50 & 7.1530 & 70.560 & 0.6560 & 0.0450 & 98.920 & 0.9130 & 0.0290 & 99.040 & 0.8730 \\
\hline
\end{tabular}

\subsubsection{Pseudo Second-Order Kinetic Model}

This model considers the adsorption process as a pseudo-chemical reaction process (chemisorption) and the overall adsorption rate is proportional to the square of the driving force. Ho and McKay (2000) expressed the kinetic rate equation in the linear form as:

$$
\frac{t}{q_{t}}=\frac{1}{k_{2} q_{e}^{2}}+\frac{t}{q_{e}}
$$

where $k_{2}$ is the rate constant of pseudo-second-order adsorption (mg/g.min), $q_{e}$ is the equilibrium solid phase concentration (mg/g) and $q_{t}$ is the solid phase concentration at time $\mathrm{t}(\mathrm{mg} / \mathrm{g})$.

The Pseudo-second-order model was applied to the kinetics data in an attempt to determine the adsorption mechanism. Table 4 summarizes the pseudo-second-order rate constants for adsorption of MG onto diatomite. As seen from Table 4, there is good agreement between the values of the equilibrium adsorption capacity, $q_{e}$ (Pred), calculated by the pseudo-secondorder model and the experimental values, $q_{e}$ (Expt). Moreover, the correlation coefficients, $\mathrm{r}^{2}$, for the pseudo-second-order model are close to one (>0.99); this confirms the feasibility of the pseudo-second-order model to simulate the experimental data and implies that the adsorption mechanism of MG onto diatomite might be chemisorption (Chiou and Li, 2003). Figure 7 further supports the pseudo-second-order model and shows the success of the model to simulate the experimental data for the adsorption of MG onto diatomite.

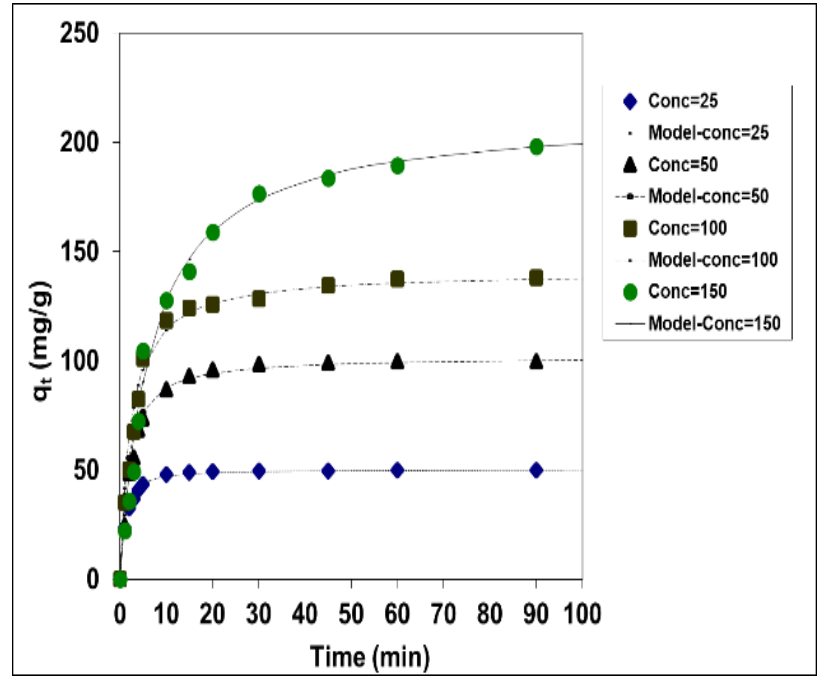

Fig. 7 Simulation of pseudo second-order model for the adsorption of MG onto diatomite. Temperature $25^{\circ} \mathrm{C}$, agitation $300 \mathrm{rpm}$, size $500-710 \mu \mathrm{m}$, mass $0.75, \mathrm{pH} 7$ and volume $1.7 \mathrm{dm}^{3}$. Concentration is in $\mathrm{ppm}$.

Table 4 Pseudo second-order rate constants for the adsorption of MG onto diatomite.

\begin{tabular}{|c|c|c|c|c|c|c|c|c|c|}
\hline $\begin{array}{c}\text { Variable } \\
\mathrm{pH}\end{array}$ & $\begin{array}{l}\mathrm{K}_{2} \times 10^{3} \\
(\mathrm{~g} / \mathrm{mg} \cdot \mathrm{min})\end{array}$ & $\begin{array}{l}\mathrm{q}_{\mathrm{e}(\text { Pred })} \\
(\mathrm{mg} / \mathrm{g})\end{array}$ & $\begin{array}{l}\mathrm{q}_{\mathrm{e}(\mathrm{Expt})} \\
(\mathrm{mg} / \mathrm{g})\end{array}$ & $\mathrm{r}^{2}$ & $\begin{array}{l}\text { Conc. } \\
(\mathrm{ppm})\end{array}$ & $\begin{array}{l}\mathrm{K}_{2} \times 10^{3} \\
\text { (g/mg.min) }\end{array}$ & $\begin{array}{l}\mathrm{q}_{\mathrm{e}(\mathrm{Pred})} \\
(\mathrm{mg} / \mathrm{g})\end{array}$ & $\begin{array}{l}\mathrm{q}_{\mathrm{e}(\mathrm{Expt})} \\
(\mathrm{mg} / \mathrm{g})\end{array}$ & $\mathrm{r}^{2}$ \\
\hline 5 & 1.440 & 131.42 & 129.81 & 0.9970 & 25 & 28.90 & 49.960 & 49.980 & 72.989 \\
\hline $7 *$ & 3.018 & 138.10 & 138.09 & 0.9940 & 50 & 5.856 & 100.63 & 99.873 & 60.970 \\
\hline 9 & 1.475 & 166.93 & 167.16 & 0.9950 & 150 & 0.696 & 201.42 & 198.58 & 31.540 \\
\hline 11 & 2.202 & 200.36 & 198.54 & 0.9990 & -------- & --------- & -------- & ------- & -------. \\
\hline \multicolumn{10}{|l|}{$\begin{array}{l}\text { Mass } \\
(\mathrm{g})\end{array}$} \\
\hline 0.25 & 0.457 & 183.28 & 176.76 & 0.9541 & & & & & \\
\hline 0.50 & 0.947 & 150.39 & 149.38 & 0.9990 & & & & & \\
\hline 1.500 & 12.04 & 99.337 & 99.350 & 0.9990 & & & & & \\
\hline
\end{tabular}

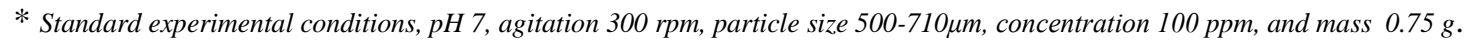




\subsubsection{Transport Number}

The transport number is usually utilized to investigate the mode of diffusion process (Yakubu and Owabor, 2018). The transport number can be expressed in a linearized form as in Eq. (5):

$$
\log \frac{q_{t}}{q_{e}}=\log K_{m}+n \log t
$$

Where $K_{m}$ is the adsorbent-adsorbate interaction coefficient and $n$ is the transport number.

The transport mechanism can be identified based on the value of $n$. According to Girish and Murty (2016), a value of $n=0.5$ would suggest the Fickian mechanism (a surface mechanism), whereas a value of $n=1$ would indicate a non-Fickian mechanism. The values of $K_{m}$ and $\mathrm{n}$ are summarized in Table 5 at different masses of diatomite. It is clear from Table 5 that the values of $\mathrm{n}$ are below 0.5 referring to the Fickian diffusion mechanism (surface diffusion) where MG interacts on the surface of diatomite. In surface diffusion, adsorbate particle migrates along the pore surface and hops from one adsorption site to another in a series of adsorption-desorption reactions (Hajjai et al., 2001).

\subsubsection{Biot Number}

Biot number is a useful tool applied to the kinetic data to analyze the rate-controlling step during the adsorption process. Biot number is a dimensionless group that relates the external mass transfer coefficient, $k_{f}$, to the intraparticle diffusion coefficient, $D_{e}$, and is given in Eq. (6) (Girish and Murty, 2016):

$$
B_{i}=\frac{k_{f} d}{D_{e}}
$$

Where $d$ is the adsorbent's particle diameter $(\mathrm{m}) ; D_{e}$ is the intraparticle diffusion coefficient $\left(\mathrm{m}^{2} / \mathrm{min}\right)$, and $k_{f}$ is the external mass transfer coefficient ( $\mathrm{m} / \mathrm{min}$ ). Intraparticle diffusion is the rate-controlling step if Biot number is greater than 100 and film diffusion is the expected rate-controlling step if Biot number is lower than 100. The intraparticle diffusion coefficients were calculated using Eq. (7) and Eq. (8) (Viegas et al., 2014):

$$
\operatorname{Ln}\left[1-F(t)^{2}\right]=-\frac{\pi^{2} D_{e}}{r^{2}} t
$$

and

$$
F(t)=\frac{q_{t}}{q_{e}}
$$

Where $r$ is the particle size radius assuming spherical geometry $(\mathrm{m})$ and $F(t)$ is the fractional attainment of equilibrium. $D_{e}$ values were calculated from the slope of the plot of $\operatorname{Ln}\left[1-F(t)^{2}\right]$ versus $t$. All the calculated values were in the range of $10^{-9}$. According to Vinod and Anirudhan (2001), the value of $D_{e}$ in the rage of $10^{-6}-10^{-8}$ indicates that film diffusion is the rate-controlling step, while for pore diffusion, the value should be in the range of $10^{-11}-10^{-13}$. Thus, the value of $D_{e}$ in the range of $10^{-9}$ may refer to the fact that the adsorption process is not purely controlled by film diffusion and particle diffusion was involved in the later stages. This is in agreement with the earlier findings of Furusawa-Smith and intraparticle diffusion models. Both models confirm that neither film diffusion nor intraparticle diffusion is the sole rate-controlling step during the whole adsorption process. The calculated Biot numbers were larger than 100 for all the experimental conditions studied which is an indication of the predominance of the intraparticle diffusion. Despite Biot number results, one cannot exclude the effect of the external mass transfer process especially during the initial period of the adsorption process and the possibility of chemisorption as indicated by the results of the pseudosecond-order model.

\subsubsection{Boyd Model}

Boyd's model is considerably used to predict the actual rate-controlling step in the adsorption process. The model is expressed as follow (Viegas et al., 2014): 


$$
\begin{array}{ll}
B_{t}=-\operatorname{Ln} \frac{\pi^{2}}{6}-\ln (1-F(t)), & \text { for } \mathrm{F}(\mathrm{t})>0.85 \\
B_{t}=\left(\sqrt{\pi}-\sqrt{\pi-\frac{\pi^{2} F(t)}{3}}\right)^{2}, \quad \text { for } \mathrm{F}(\mathrm{t})<0.85
\end{array}
$$

According to this model, if the plot of $B_{t}$ versus time is linear and passes through the origin, then intraparticle diffusion is the rate-controlling step. On the other hand, if the plot is nonlinear or linear but does not pass through the origin, then film diffusion or chemisorption is the rate-controlling step (Viegas et al., 2014). According to Viegas et al. (2014), Boyd's plots often have a multilinear nature. Figure 8 displays the Boyd plot for the adsorption of MG onto Jordanian diatomite at two different concentrations. It is obvious from the figure the multilinear nature of the Boyd plot. Boyd plot reveals that the intraparticle diffusion mechanism is not the dominant mechanism and indicates the involvement of other mechanisms in the adsorption process of MG onto diatomites such as film diffusion and chemisorption.

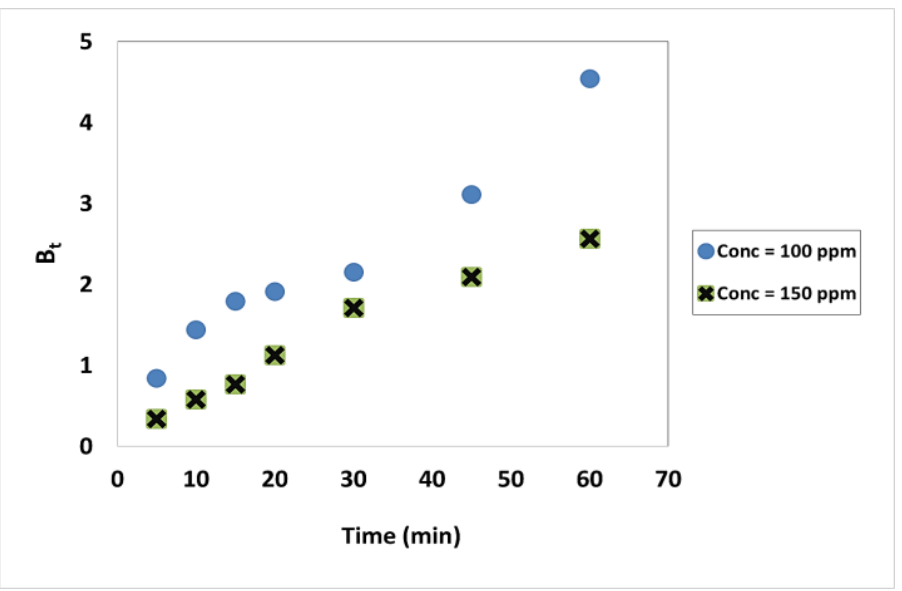

Fig. 8 Boyd plot for the adsorption of MG onto diatomite.

\subsubsection{Elovich Model}

Elovich model is usually applied to chemisorption systems in which the adsorbent is heterogeneous. The linear form of the Elovich equation is written as follow (Ramachandran et al., 2011):

$$
q_{t}=\frac{1}{\beta} \operatorname{Ln}(\alpha \beta)+\frac{1}{\beta} \operatorname{Lnt}
$$

Where $\alpha$ is the initial rate of adsorption ( $\mathrm{mg} / \mathrm{g} \cdot \mathrm{min})$ and $\beta$ is the adsorption constant related to the extent of surface coverage and the activation energy for chemisorption $(\mathrm{g} / \mathrm{mg})$. Figure 9 shows the goodness of fit of the Elovich model to the experimental data for the adsorption of MG onto Jordanian diatomite. It is clear from the figure that the model was able to simulate the kinetic data quite well and this supports the earlier findings of the equilibrium and kinetic studies. Equilibrium study showed that the experimental data are best presented by the Freundlich model and this confirms the heterogeneous nature of diatomite. Moreover, the kinetics study revealed that the adsorption mechanism might be chemisorption through the application of the pseudo-second-order model.

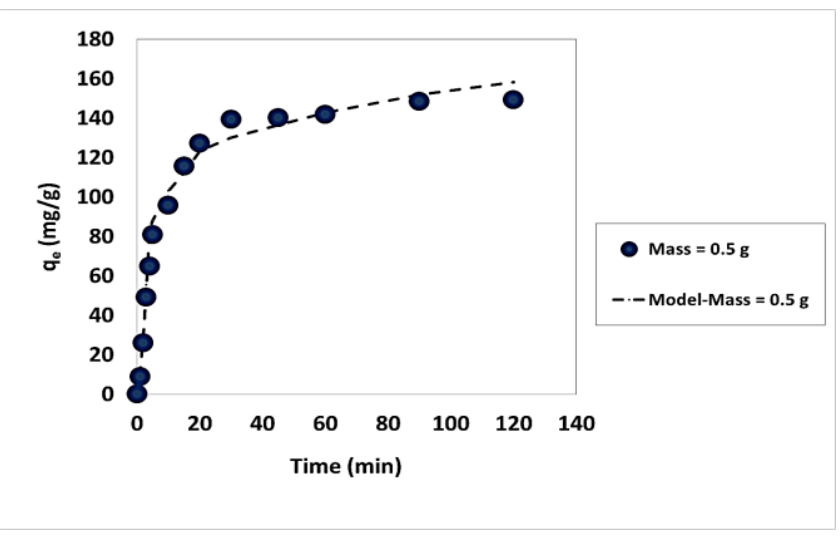

\section{Conclusions}

Fig. 9 Simulation of Elovich model for the adsorption of MG onto diatomite.

Adsorption kinetics that governs the removal of MG from aqueous solution was investigated under various conditions. The degree of removal of MG was found to be dependent on the experimental conditions. The higher amount of Jordanian diatomite showed a significant increase in the rate of MG adsorption with approximately $99 \%$ of dye removal. The kinetics performance of Jordanian diatomite was very well at the basic condition. The higher the initial MG concentration, the slower the rate of adsorption. Kinetics data were in good agreement with the pseudo-second-order kinetic model which confirms the chemisorption's nature of the adsorption process of MG onto Jordanian diatomite. The Elovich model was able to describe the adsorption process of MG and confirms the heterogeneous nature of Jordanian diatomite. The overall rate of the adsorption of MG onto Jordanian diatomite is controlled by film and intraparticle diffusion processes; during an initial period, the external mass transfer is the predominant mechanism followed by intraparticle diffusion with the possibility of chemisorption. 


\section{Nomenclature}

\begin{tabular}{|c|c|c|}
\hline $\mathrm{C}_{\mathrm{o}}$ & $=$ Initial dye concentration & {$\left[\mathrm{mg} / \mathrm{dm}^{3]}\right.$} \\
\hline $\mathrm{C}_{\mathrm{t}}$ & $=$ Concentration of MG solution at time $\mathrm{t}$, & {$\left[\mathrm{mg} / \mathrm{dm}^{3}\right]$} \\
\hline $\mathrm{d}$ & $=$ Adsorbent's particle diameter & {$[\mathrm{m}]$} \\
\hline$D_{e}$ & $=$ Intraparticle diffusion coefficient & {$\left[\mathrm{m}^{2} / \mathrm{in}\right]$} \\
\hline $\mathrm{F}(\mathrm{t})$ & $=$ Fractional attainment of equilibrium & {$[-]$} \\
\hline $\mathrm{k}_{\mathrm{f}}$ & $=$ External mass transfer coefficient & {$[\mathrm{m} / \mathrm{min}]$} \\
\hline $\mathrm{k}_{\mathrm{L}}$ & $=$ Langmuir constant & {$\left[\mathrm{dm}^{3} / \mathrm{g}\right]$} \\
\hline $\mathrm{K}_{\mathrm{m}}$ & $=$ Adsorbent-adsorbate interaction coefficient & {$[-]$} \\
\hline $\mathrm{k}_{\mathrm{p}}$ & $=$ Intraparticle diffusion rate constant & {$\left[\mathrm{mg} / \mathrm{g} \cdot \mathrm{min}^{1 / 2}\right]$} \\
\hline $\mathrm{K}_{2}$ & $=$ Rate constant of pseudo second-order adsorption & [mg/g.min] \\
\hline $\mathrm{m}$ & $=$ Mass of the diatomite & {$[\mathrm{g}]$} \\
\hline $\mathrm{m}_{\mathrm{y}}$ & $=$ Coefficient of adsorbent & {$\left[\mathrm{g} / \mathrm{dm}^{3}\right]$} \\
\hline $\mathrm{n}$ & $=$ Transport number & {$[-]$} \\
\hline $\mathrm{q}_{\mathrm{e}}$ & $=$ Equilibrium solid phase concentration & {$[\mathrm{mg} / \mathrm{g}]$} \\
\hline $\mathrm{q}_{\mathrm{t}}$ & $=$ Amount of MG adsorbed at time $\mathrm{t}$ & {$[\mathrm{mg} / \mathrm{g}]$} \\
\hline $\mathrm{r}$ & $=$ Particle size radius assuming spherical geometry & {$[\mathrm{m}]$} \\
\hline $\mathrm{S}_{\mathrm{s}}$ & $=$ Specific surface area & {$\left[\mathrm{m}^{-1}\right]$} \\
\hline $\mathrm{t}$ & $=$ Time & {$[\mathrm{min}]$} \\
\hline V & $=$ Volume of MG solution & {$\left[\mathrm{dm}^{3}\right]$} \\
\hline$\alpha$ & $=$ Initial rate of adsorption & [mg/g.min] \\
\hline$\beta$ & $=$ Adsorption constant related to the extent of surface coverage & {$[\mathrm{g} / \mathrm{mg}]$} \\
\hline
\end{tabular}

\section{References}

Alali, J., Diatomite, Ministry of Energy and Mineral Resources, Jordan. (2015).

Arivoli, S., Hema, M. and Prasath, P. “Adsorption of Malachite Green onto Carbon Prepared from Borassus Bark”, The Arabian J. Sci, Eng., 34, 31-42 (2009).

Aazza, M., Moussout, H., Marzouk R., and Ahlafi, H. "Kinetic and Thermodynamic Studies of Malachite Green Adsorption on Alumina”, J. Mat. Envi. Sci., 8, 2694-2703 (2017).

Benmaamar, Z., Boutoumi, H., Hamitouche, H., Benmaamar, H., Mazari, S., Benmaamar, A., and Aggoun, A. "Simulation of Adsorption Kinetics of Malachite Green onto Coffee Residues", Revue Science des Matériaux, Laboratoire, 8, 1-11 (2016).

Chiou, M., and Li, H. "Equilibrium and Kinetics Modelling of Adsorption of Reactive Dye on Cross-Linked Chitosan Beads", J. Haz. Mat. B, 93, 233-248 (2002).

Chiou, M. S., and Li, H. "Adsorption Behaviour of Reactive Dye in Aqueous Solution on Chemical Cross-Linked Chitosan Beads", Chemosphere, 50, 1095-1105 (2003).

Dhahir, S., Abdul-Hussein, E., Sarhan S., and Faraj, N. "Adsorption of Malachite Green Dye From Aqueous Solution onto Iraqi Raw Al-Hussainiyat Clay", Eur. Chem. Bull., 2, 866-872 (2013).

El Qada, E., "Adsorption of Malachite Green by Jordanian Ores Diatomite I: Equilibrium Study", Jordanian J. of Eng. and Chem. Indus., 2, 94-99, (2019).

Furusawa, T. and Smith, J. "Fluid-Particle and Intraparticle Mass Transport Rates in Slurries", Ind. Eng. Chem. Fundam., 12, 197-203 (1973).

Georgiadis, I., Papadopoulos, A., Filippidis, A., Godelitsas, A., Tsirambides A., and Vogiatzis, D. "Removal of Malachite Green Dye from Aqueous Solutions by Diasporic Greek Raw Bauxite”, Bulletin of the Geological Society of Greece, 47, 927-933 (2013).

Girish, C., and Murty, V. "Mass Transfer Studies on Adsorption of Phenol from Wastewater Using Lantana Camara, Forest Waste”, Int. J. Chem. Eng., 2, 1-11 (2016)

Guo, X. and Wang, J. “A general kinetic model for adsorption: Theoretical analysis and modeling”, J. Molecular Liquids, 288, 1-8 (2019).

Hajjai, M., Kacim, S., Alami, A., El Bouadili A., and El Mountassir, M. "Chemical and Mineralogical Characterisation of a Clay Taken from the Moroccan Meseta and a Study of the Interaction between Its Fine Fraction and Methylene Blue", App. Clay Sci., 20, 1-12 (2001).

Hasanzadeh, M., Simchi A., and Far, H. "Nanoporous composites of activated carbon-metal organic frameworks for organic dye adsorption: Synthesis, adsorption mechanism and kinetics studies", J. Ind. and Eng. Chem., in press (2019).

Hema, M. and Arivoli, S. “Adsorption Kinetics and Thermodynamics of Malachite Green Dye onto Acid Activated Low Cost Carbon”, J. Appl. Sci. Envi. Manage., 12, 43-51 (2008).

Heydaria, R. and Khavarpour, M. "Adsorption of Malachite Green from Aqueous Solution by Nanozeolite Clinoptilolite: Equilibrium, Kinetic and Thermodynamic Studies", Int. J. Eng., 31, 1-11 (2018).

Ho, Y., "Review of second-order models for adsorption systems", J. Haz. Mat. B, 136, 681-689 (2006)

Ho, Y., and McKay, G. "The Kinetics of Sorption of Divalent Metal Ions onto Sphagnum Moss Peat", Wat. Res., 34, 735-742 (2000)

Krishnan, K., and. Anirudhan, T. "Removal of Mercury (II) from Aqueous Solutions and Chlor-Alkali Industry Effluent by Steam Activated and Sulphurised Activated Carbons Prepared from Bagasse Pith: Kinetics and Equilibrium Studies", J. Haz. Mat. B, 92, 161-183 (2002).

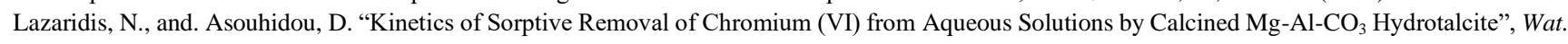
Res., 37, 2875-2882 (2003).

Litefti, K., Freire, M., Stitou M., and González-Álvarez. J. "Biosorption of cationic textile dyes by a forest industry residue: Pinus pinaster bark" $15^{\text {th }}$ International Conference on Environmental Science and Technology, Greece: 2017.

Mckay, G., Bino, M., and Altamemi, A. "External Mass Transfer during the Adsorption of Various Pollutants onto Activated Carbon", Wat. Res., 20, 435442 (1986).

Mittal, A., "Use of Hen Feathers as Potential Adsorbent for the Removal of a Hazardous Dye, Brilliant Blue FCF, from Wastewater", J. Haz. Mat. B, 128, 233-239 (2006).

Nethajia, S., Sivasamya, A., Thennarasua G., and Saravanan, S. "Adsorption of Malachite Green Dye onto Activated Carbon Derived from Borassus Aethiopum Flower Biomass", J. Haz. Mat., 181, 271-280 (2010).

Pan, X., and Zhang, D. “Removal of Malachite Green from Water by Firmiana Simplex Wood Fiber”, Elect. J. Biotech., 12, 4-14 (2009). 
Ramachandran, P., Vairamuthu R., and Ponnusamy, S. “Adsorption Isotherms, Kinetics, Thermodynamics and Desorption Studies of Reactive Orange16 on Activated Carbon Derived from Anabas Comosus (L.) Carbon”, ARPN J. Eng. App. Sci., 6, 15-26 (2011).

Regazzoni, A., "Adsorption kinetics at solid/aqueous solution interfaces: On the boundaries of the pseudo-second order rate equation", Colloids and Surfaces A: Physicochemical and Engineering Aspects, in press (2019).

Rudzinski, W. and Plazinski, W. "Kinetics of Gas Adsorption in Activated Carbons, Studied by Applying the Statistical Rate Theory of Interfacial Transport", Phys. Chem. B, 105, 6858-6866 (2001).

Santhi, M., Kumar P., and Muralidharan, B. "Removal of Malachite Green Dyes By Adsorption onto Activated Carbon - $\mathrm{MnO}_{2}-$ Nanocomposite - Kinetic Study and Equilibrium Isotherm Analyses", J. App. Chem., 8, 33-41 (2015).

Sartape, A., Mandhare, A., Jadhav, V, Raut, P., Anuse, M., and Kolekar, S. "Removal of Malachite Green Dye from Aqueous Solution with Adsorption Technique Using Limonia Acidissima (Wood Apple) Shell as Low Cost Adsorbent”, Arabian J. chem.,10, S3229-S3238 (2017).

Sawasdee, S., and Watcharabundit, P. "Equilibrium, Kinetics and Thermodynamic of Dye Adsorption by Low-Cost Adsorbents", Int. J. Chem. Eng. Appl., 6, 444-449 (2015).

Sharma, S., Pant K., and Tiwari, D. "Batch Adsorption Studies for Malachite Green Dye Removal from Wastewater Using Biomass-Based Adsorbent", Bulletin of the South Ural State University. Ser. Chemistry, 8, 51-60 (2016).

Shirmardi, M., Mahvi., A., Hashemzadeh, B., Naeimabadi, A., Hassani, G., and Niri, M. "The Adsorption of Malachite Green (MG) as a Cationic Dye onto Functionalized Multi Walled Carbon Nanotubes”, Korean J. Chem. Eng., 30, 1603-1608 (2013).

Song, Y., Ding, S., Chen, S., Xu, H., Mei Y., and Ren, J. "Removal of Malachite Green in Aqueous Solution by Adsorption on Sawdust", Korean J. Chem. Eng., 32, 2443-2448 (2015).

Thilagavathi, M., Arivoli S., and Vijayakumaran, V. “Adsorption of Malachite Green from Waste Water Using Prosopis Juliflora Bark Carbon”, Kuwait J. Sci., 42, 120-133 (2015).

Ullah, H., Nafees, M., Iqbal, F., Awan, M., Shah A., and Waseem, A. “Adsorption Kinetics of Malachite Green and Methylene Blue from Aqueous Solutions Using Surfactant-modified Organoclays”, Acta Chim. Slov., 64, 449-460 (2017).

Viegas, R., Campinas, M., Costa H., and Rosa, M. "How Do the HSDM and Boyd's Model Compare for Estimating Intraparticle Diffusion Coefficients in Adsorption Processes", Adsorption, 20, 737-746 (2014).

Vinod, V., and Anirudhan, T. "Sorption of Tannic Acid on Zirconium Pillared Clay", J. Chem. Technol. Biotechnol., 77, 92-101 (2001)

Yakubu, E., and Owabor, C. "The Effect of Mass Transfer Resistance on the Adsorption Rate of Phenol in Soil Sediments", American J. Envi. Sci. Eng., 2,56-64 (2018). 